\title{
Minimally invasive liver surgery-whither else but straight ahead?
}

\author{
Carolijn L. Nota, Inne H. M. Borel Rinkes, Jeroen Hagendoorn \\ Department of Surgical Oncology, UMC Utrecht Cancer Center and Utrecht University, Utrecht, The Netherlands \\ Correspondence to: Dr. Jeroen Hagendoorn. Department of Surgical Oncology, UMC Utrecht Cancer Center and Utrecht University, Heidelberglaan \\ 100, 3584 CX Utrecht, The Netherlands. Email: j.hagendoorn-3@umcutrecht.nl. \\ Provenance: This is an invited Editorial commissioned by Editor-in-Chief Minhua Zheng (Department of General Surgery, Ruijin Hospital, Shanghai \\ Jiaotong University School of Medicine, Shanghai Minimal Invasive Surgery, Shanghai, China). \\ Comment on: Martínez-Cecilia D, Fontana M, Siddiqi NN, et al. Laparoscopic parenchymal sparing resections in segment 8: techniques for a \\ demanding and infrequent procedure. Surg Endosc 2018;32:2012-9.
}

Received: 28 February 2018; Accepted: 08 March 2018; Published: 23 March 2018.

doi: $10.21037 /$ ales.2018.03.06

View this article at: http://dx.doi.org/10.21037/ales.2018.03.06

Overwhelming clinical evidence supports the use of minimally invasive liver surgery (MILS), at least in case of minor hepatectomy, given its benefits in perioperative outcome measures and postoperative recovery $(1,2)$. Conceptually, these findings make sense in resections where the volume of the liver remnant is large enough to not expect significant post-hepatectomy liver insufficiency and reconvalescence is mostly dependent on the surgical incision. As such, MILS fits perfectly into the concept of enhanced recovery after surgery (3). Scientifically, the consensus meetings of Louisville, Marioka, and Southampton have delineated a number of indications and technical guidelines on how MILS can best be performed, in what type of liver resections, and by whom (that is, in terms of "experience") $(4,5)$. Promising data coming from large international institutions have, surprisingly, so far not translated in the widespread adoption of MILS in many countries and hospitals. In the Netherlands, for example the percentage of minor liver resections performed by laparoscopy or robotics was around 30\% in 2016, up from $11 \%$ in 2014 (6). So, although MILS is on the rise, liver surgery, for the largest part, remains an open undertaking. Evidently, we need more consistent concepts of technique (per type of hepatectomy: exposure, parenchymal transection, control of blood loss), visualization (ultrasonographic or fluorescent delineation of the tumor), reproducibility, and implementation/learning curve. In our view, we should weigh novel reports on MILS with that perspective in mind.

Martínez-Cecilia et al. present such a thoughtful study that lays out in detail a technique for laparoscopic liver resection of segment 8 and validates its premise in a retrospective, single-center cohort (7). The authors present 30 patients with mostly colorectal liver metastases (out of a total cohort of 650 laparoscopic liver resections between 2003 and 2016; 13 of whom had isolated segment 8 resection) in whom a fully transabdominal segment 8 resection was performed, using a standardized "reversed L" configuration for trocar placement with four straight transection planes around the lesion. Ultrasonic devices and the cavitron ultrasonic surgical aspirator (CUSA) were used for parenchymal transection (under Pringle manoeuver in $57 \%$ ), while ultrasound guided the oncological margins. The authors report acceptable outcomes: operative time $210 \mathrm{~min}$, conversion rate $3.4 \%$, R0 92\% (segment 8 specific), major morbidity $7 \%$, median hospital stay 4 days. In addition, long-term oncologic outcomes are as good as can be expected for this indication. This small series nicely shows a consistently employed, less traumatic/fully transabdominal approach (in contrast to the placement of transthoracic trocars or hand-assistance that others have propagated) specifically for resections of segment 8 ; oncological control and its pitfalls (namely, the deep transection plane) are clearly described. There are also aspects that remain unclear from this study, e.g., the appropriateness of the technique for redo-resections, larger tumors, primary tumors such as HCC and cholangiocarcinoma, and combined resections, e.g., colectomy or hepatic pedicle lymphadenectomy. Also, the data come from a center with large volume $( \pm 50$ MILS per year as per the data provided in their study) and patients were selected. That does not diminish the fact, 
however, that these data may be seen as a good step towards reproducibility and implementation elsewhere.

Several questions can be raised. First, where do we take research? With extensive evidence in favor of MILS for accessible (segments $2 / 3,4 \mathrm{~B}, 5,6$ ) minor resections $(1,2)$, MILS for that indication must now be considered standard of care. Provided techniques are consistent and reproducible, the benefit of MILS for "difficult" resections (segment 7, 8, 4A, 1, as well as, to a lesser degree, "standard" left and right hepatectomy) in experienced hands is obvious $(2,8)$. Therefore, further randomized studies for these indications seem redundant (although several more are underway) and large, multi-institutional cohort series may just provide sufficient clinical evidence. Second, how to further improve actual implementation of MILS? Successful introduction of MILS may be hampered by inexperience with laparoscopy of a particular surgeon, lack of training (or volume) in a standardized technique, or technical constraints in difficult resection locations. These can be overcome with keeping adequate case volumes and systematic proctoring by (or referral to) surgeons that are experienced in these resections. At the same time, robotic surgery may provide the flexibility needed in the full spectrum of liver resections and be the technique of choice for surgeons that do not now have extensive experience in or find themselves constrained by conventional laparoscopy. Robotic liver surgery has, in this context, been suggested as having potential advantages in terms of indications (e.g., posterior resections), conversions, and learning curve (9-12). Last, how do we see future developments in MILS? Surgical technique will be further refined. In conventional laparoscopy, ultrasonic devices and CUSA are now standard techniques, while inflow control is provided by improvised methods of hepatic pedicle clamping. Flexible tip instruments and sealing devices especially designed for liver parenchyma will be of help. In robotics, bipolar devices (PK, Maryland), the Vessel Sealer (wristed device that both coagulates and cuts) along with wristed clip appliers, staplers, and, of course, sutures are used. Wristed instrumentation, 3D view, and scaled movements are attractive assets in liver surgery, especially for difficult-to-reach locations, hilar dissection, and curved transection planes. However, smaller size coagulation devices or CUSA-like devices would improve the technique. We envision that in the next decade or so, conventional laparoscopy and robotic laparoscopy techniques are going to merge. Ongoing innovation coming from the current largest provider of robotic systems, Intuitive Surgical, alongside a number of expected entrants into the robotic surgery market (amongst whom Medtronic, Verb Surgical, TransEnterix, Cambridge Medical, Titan Medical and others) will provide an unprecedented impulse for innovation and cost-competitiveness. Visualization and oncological margin control in parenchyma sparing surgery will be further improved by applications such as FireFly imaging (indocyanine-green biliary contrast) (13), integrated augmented-reality navigation (14), and development of more flexible minimally invasive ultrasound systems (15). Thus, minimally invasive surgery seems on the brink of a transformation that reminds us of the progress that medicine as a whole was making half a century ago and led to the famous words "Whither medicine? Why, whither else but straight ahead" (16)? We hope then that expanding clinical implementation will be of benefit to a broader group of patients.

\section{Acknowledgements}

The authors thank Dr. Quintus Molenaar (UMC Utrecht) and Dr. Yuman Fong (City of Hope National Cancer Center, Duarte, CA, US) for helpful discussions on the topic of MILS.

\section{Footnote}

Conflicts of Interest: The authors have no conflicts of interest to declare.

\section{References}

1. Ciria R, Cherqui D, Geller DA, et al. Comparative Shortterm Benefits of Laparoscopic Liver Resection: 9000 Cases and Climbing. Ann Surg 2016;263:761-77.

2. Fretland ÅA, Dagenborg VJ, Bjørnelv GMW, et al. Laparoscopic Versus Open Resection for Colorectal Liver Metastases: The OSLO-COMET Randomized Controlled Trial. Ann Surg 2018;267:199-207.

3. Melstrom LG, Warner SG, Woo Y,et al. Selecting incision-dominant cases for robotic liver resection: towards outpatient hepatectomy with rapid recovery. HepatoBiliary Surg Nutr 2017. [Epub ahead of print].

4. Buell JF, Cherqui D, Geller DA, et al. The international position on laparoscopic liver surgery: The Louisville Statement, 2008. Ann Surg 2009;250:825-30.

5. Wakabayashi G, Cherqui D, Geller DA, et al. Recommendations for laparoscopic liver resection: a report from the second international consensus conference held 
in Morioka. Ann Surg 2015;261:619-29.

6. Dutch Institute for Clinical Auditing, Jaarrapportage 2016. Available online: https://dica.nl/media/993/DICA-2016jaarverslag.pdf

7. Martínez-Cecilia D, Fontana M, Siddiqi NN, et al. Laparoscopic parenchymal sparing resections in segment 8: techniques for a demanding and infrequent procedure. Surg Endosc 2018;32:2012-9.

8. Nota CL, Rinkes IHB, Molenaar IQ, et al. Robot-assisted laparoscopic liver resection: a systematic review and pooled analysis of minor and major hepatectomies. HPB (Oxford) 2016;18:113-20.

9. Tsung A, Geller DA, Sukato DC, et al. Robotic versus laparoscopic hepatectomy: a matched comparison. Ann Surg 2014;259:549-55.

10. Nota CLMA, Molenaar IQ, van Hillegersberg R, et al. Robotic liver resection including the posterosuperior segments: initial experience. J Surg Res 2016;206:133-8.

11. Gheza F, Mangano A, Giulianotti PC. Conversion During

doi: 10.21037/ales.2018.03.06

Cite this article as: Nota CL, Borel Rinkes IH, Hagendoorn J. Minimally invasive liver surgery-whither else but straight ahead? Ann Laparosc Endosc Surg 2018;3:25.
Laparoscopic Liver Resections: A Step Forward. Ann Surg 2018. [Epub ahead of print].

12. O'Connor VV, Vuong B, Yang ST, et al. Robotic Minor Hepatectomy Offers a Favorable Learning Curve and May Result in Superior Perioperative Outcomes Compared with Laparoscopic Approach. Am Surg 2017;83:1085-8.

13. Takahashi H, Zaidi N, Berber E. An initial report on the intraoperative use of indocyanine green fluorescence imaging in the surgical management of liver tumorss. J Surg Oncol 2016;114:625-9.

14. Pessaux P, Diana M, Soler L, et al. Towards cybernetic surgery: robotic and augmented reality-assisted liver segmentectomy. Langenbecks Arch Surg 2015;400:381-5.

15. Kingham TP, Leung U, Kuk D, et al. Robotic Liver Resection: A Case-Matched Comparison. World J Surg 2016;40:1422-8.

16. Whither medicine? BMJ 2006;333:0-f. Available online: https://doi.org/10.1136/bmj.333.7567.0-f 